\title{
Modernizações em Minas Gerais
}

Elementos teórico-conceituais e clivagens geohistóricas

The modernization process in Minas Gerais: Theoretical and conceptual elements, and geohistorical cleavages

Modernizaciones en Minas Gerais: Elementos teóricos-conceptuales y esciciones geohistóricas

Modernisations dans Minas Gerais : Éléments théoriques et conceptuels, et clivages géohistoriques

\section{Alfredo Costa e Ralfo Edmundo da Silva Matos}

\section{(2) OpenEdition}

Journals

Edição electrónica

URL: https://journals.openedition.org/terrabrasilis/5986

DOI: 10.4000/terrabrasilis.5986

ISSN: 2316-7793

Editora

Rede Brasileira de História da Geografia e Geografia Histórica

Refêrencia eletrónica

Alfredo Costa e Ralfo Edmundo da Silva Matos, «Modernizações em Minas Gerais», Terra Brasilis

[Online], 13 | 2020, posto online no dia 06 novembro 2020, consultado o 05 dezembro 2022. URL:

http://journals.openedition.org/terrabrasilis/5986 ; DOI: https://doi.org/10.4000/terrabrasilis.5986

Este documento foi criado de forma automática no dia 5 dezembro 2022.

All rights reserved 


\section{Modernizações em Minas Gerais}

Elementos teórico-conceituais e clivagens geohistóricas

The modernization process in Minas Gerais: Theoretical and conceptual

elements, and geohistorical cleavages

Modernizaciones en Minas Gerais: Elementos teóricos-conceptuales y esciciones

geohistóricas

Modernisations dans Minas Gerais : Éléments théoriques et conceptuels, et

clivages géohistoriques

Alfredo Costa e Ralfo Edmundo da Silva Matos

\section{NOTA DO AUTOR}

Este texto é um desdobramento da tese de doutorado "Modernização e reestruturações territoriais em Minas Gerais", defendida por Costa em 2018.

\section{Introdução}

1 A principal função da geografia histórica é se debruçar sobre mudanças e permanências geográficas ao longo do tempo e em um determinado recorte espacial (Carneiro, 2013). Pode ser considerado um campo de investigação que atua na interface entre a geografia e a história em busca da caracterização de ambientes geográficos do passado (Carneiro \& Matos, 2012). Como método científico, compreende um rol de princípios que se configuram como chave epistemológica de leitura e interpretação da genealogia de processos socioespaciais passados e presentes (Soares, 2013).

2 Soares (2013) relaciona alguns marcos orientadores para a realização de estudos legitimamente contextualizados na geografia histórica. Destacam-se os seguintes:

1. os lugares possuem participação irredutível na consecução de resultantes temporais, ou seja, os relacionamentos espaciais, a distribuição territorial dos fenômenos e a forma 
pela qual os fenômenos se combinam, fazem uma diferença crucial na dinâmica histórica;

2. é preciso voltar a atenção às diferenças, aos limites, às singularidades e aos relacionamentos espaciais, é necessário dar voz à história espacializada para retirar das geografias do passado elementos explicativos de acontecimentos históricos fundamentais;

3. fatos históricos não resultam de necessidades inelutáveis, dependem em boa parte de fatores aleatórios, culturais, psicológicos, políticos e econômicos etc., isto é, a incerteza e as trajetórias inesperadas fazem parte do mundo;

4. causas próximas e causas distantes, horizontalidades (estruturas internas) e verticalidades (estruturas externas), processos de ordem local e processos de ordem vasta articulam-se de forma tensional, e essa tensão relacional entre escalas processuais dá ocasião a espaços estruturais de autonomia, iniciativa, diferenciação e singularidade em face de estruturas escalares mais amplas; assim, a Geohistória, que tem no conhecimento da gênese dos processos sua preocupação primeira, obriga-se necessariamente a examinar a natureza da relação espaço/sociedade na estrutura do devir (Soares, 2013: 52).

David Harvey é definitivo: "as experiências espaciais e temporais são veículos primários da codificação e reprodução das relações sociais” (2011: 225). A reunião da geografia com a história e a utilização da historicidade como via para a compreensão de objetos e processos sociais é útil à reconstrução das geografias do passado (Silva, 2007; Moraes, 2012; Corrêa, 2016). Sem dúvidas, a reflexão histórica é parte constituinte da geografia humana, ainda que seja preciso admitir, ensina Abreu (2000), a incapacidade de se recuperar todas as evidências do passado. $O$ autor ressalta, no entanto, que tal incapacidade não deve desencorajar os esforços de se aproximar de realidades passadas e de analisar geograficamente seus vestígios, materializados em documentos, objetos, arquitetura e no traçado de estradas, entre outros. Ao citar Le Goff (1990), pondera a necessidade do cuidado com a análise de tais vestígios, principalmente ao se admitir que os objetos mais duráveis e as próprias instituições de memória são, via de regra, criação de classes poderosas, e geralmente preservam lembranças seletivas do passado. Nesse sentido, tais atestados de memória seriam também atestados do poder.

É no contexto da reconstituição do passado que se situa a importância de se expandir o olhar sobre o território de Minas Gerais, unidade geográfica de análise deste estudo. 0 artigo em tela tem por objetivo apresentar uma narrativa sobre as modernizações que Minas Gerais experimentou desde o século XVIII, sem se prender a aspectos empíricos, tarefa já empreendida em outros trabalhos realizados e que dão suporte a essa narrativa-síntese. Intenciona-se, de maneira específica, evidenciar que o território mineiro passou por importantes mudanças estruturais e modernizadoras desde o século XVIII, as quais denotaram pioneirismo no processo de modernização urbana, reestruturação econômica e territorial. ${ }^{1}$

50 artigo é dividido em três seções. Na primeira, são examinados - sob a perspectiva da geografia histórica em suas clivagens transdisciplinares - os conceitos e elementos teóricos dos quatro principais fatores a que atribuímos as modernizações e reestruturações mineiras: o território como fator indispensável à compreensão das dinâmicas socioeconômicas; a modernidade e seus fatores de impulsão; as elites; e o fator urbano ou urbano-industrial. 
6 A segunda seção, denominada "a peculiar trajetória mineira rumo à modernização", traz uma coleção de argumentos, apresentados em ordem cronológica, que demonstram como as reestruturações econômicas e territoriais assistidas em Minas Gerais evidenciam o pioneirismo mineiro nos processos de modernização assistidos no Brasil ao longo de 250 anos. Cabe observar que a literatura sobre o tema é vasta e, por isso, foram selecionadas as principais obras que apontam a concretude do fenômeno descrito.

7 A terceira e um última seção do artigo é composta pelas considerações finais, onde são retomados os quatro fatores explicativos enunciados, articulados aos principais argumentos que corroboram a hipótese sobre a modernização e reestruturação econômica mineira.

8 Diante desse escopo disciplinar, convém iniciar nossa revisão conceitual pelas questões epistemológicas.

\section{Elementos teórico-conceituais}

9 Os elementos teórico-conceituais serão abordados a seguir em quatro subseções, por sua vez baseadas em quatro conceitos-chave deste artigo - território, modernização, elites e urbanização -, na perspectiva de que são basilares para a compreensão das reestruturações verificadas em Minas Gerais desde 1750.

\subsection{0 território como fator indispensável à compreensão da dinâmica socioeconômica}

10 Para Maurício de Abreu (1998), o passado é uma dimensão singular que se materializa na paisagem, que é percebida no cotidiano dos lugares e preservada em instituições, e que acompanha o processo de desenvolvimento da sociedade: é parte do presente e da idealização do futuro. Por pensar assim, ele afirma que qualquer pesquisa sobre o passado deve buscar recuperar não apenas as suas formas materiais, mas também aquilo que não deixou marcas na paisagem e que pode ser reavivado nos acervos das instituições de memória.

11 O espaço tem papel relevante no estabelecimento da totalidade, que interfere e repercute na moldagem das relações sociais, na medida em que, por sua conformação física, política e ideológica, define a criação, permanência ou extinção de determinados usos e ocupações (Carneiro, 2013). Reis $(2005)$ e Soares $(2013,2016)$ apontam que as realidades do espaço possuem incontáveis origens e são frutos de processos de larga escala. Em sua essência, ambos buscam a compreensão de sua capacidade de atração ou repulsão de determinados processos socioespaciais, colocando-o como parte componente das realidades socioeconômicas que se desenvolvem, por excelência, em circunstâncias concretas e diferenciáveis.

12 Nesse sentido, apresentam uma sofisticação da ideia de território, ${ }^{2}$ que deixa de ser mero receptáculo - utensílio descritivo - das relações de dominação e mobilidade (Raffestin, 1993), e passa a ser interpretado como parte orgânica e de natureza ontológica da genealogia dos processos, emprestando a eles caráter de imprevisibilidade e volatilidade. Assim, para Reis (2005), 
(..) o que está aqui em causa não é o território como conjunto físico de paisagens materiais, mas o território como expressão e produto das interações que os atores protagonizam. O território, nestas circunstâncias, é proximidade, atores, interações. E é também um elemento crucial da matriz de relações que define a morfologia do poder nas sociedades contemporâneas. (Reis, 2005: 59)

Reis (2005) não perde de vista que o território é dinâmico, heterogêneo e que circunscreve relações de poder. Mas vai além: identifica-o como elemento definidor da morfologia das relações de poder que, por não serem lineares, requerem atenção e investigação particulares. Soares (2013) sistematiza as concepções de Reis sobre o território em três ideias-chave:

1. os territórios não são a simples expressão da produção de escalas do Estado, do mercado, dos sistemas socioeconômicos mais amplos; não são apenas canais de reprodução de ordens mais vastas. Eles possuem (...) condição própria e lugar específico nas ordens (e nas desordens) societais (Reis, 1995: 3), daí sua materialidade, seu significado ontológico, não são anulados pela produção social das escalas;

2. a relação entre mobilidades e territorializações é muito mais do que uma justaposição de fatores que influenciam as dinâmicas econômicas; é uma tensão que reclama o polimorfismo estrutural, que sugere a existência de espaços estruturais de autonomia e iniciativa, que reafirma a [...] noção de que a incerteza e as trajectórias inesperadas são também parte do mundo. (Reis, 1995: 10); e

3. para entender o poder, é preciso [...] contrapor às visões lineares do poder a ideia de morfologia do poder e ao desenvolvimento funcionalista a noção de polimorfismo social. (Reis, 1995: 18 apud Soares, 2013: 41-42)

Soares (2013) assevera que as estruturas materiais não são passivas, mas integram o mundo onde se dão as relações e as trocas. Assim, conclui que a epistemologia territorial contribui para o reconhecimento de que o território é detentor de preciosas informações sobre a estruturação e dinâmica das sociedades, suas formas de reprodução e idiossincrasias.

Em síntese, o território, como categoria de análise espacial, é testemunha e veículo das transformações (Haesbaert, 1990). Ali encontram-se marcas de guerras, monumentos de culto e memória, enfim, signos de permanência e de mudança com múltiplos sentidos e múltiplas possibilidades de vivência. Por isso, a prática geográfica demanda do analista a capacidade de realizar sínteses através de conexões espaciais em diferentes escalas, e exige que tais conexões não se restrinjam ao tempo presente, mas que incorporem a interconexão entre recuperação do passado e a prospecção do futuro (Abreu, 2000).

\subsection{Modernidade e fatores de impulsão}

16 A modernidade como processo histórico, como etapa específica da trajetória histórica, abre-se em diversas dimensões, admite inúmeras caracterizações, periodizações, conceituações. Trata-se de um processo aberto, pluridimensional, polissêmico, com diversas interpretações, tais como técnico-materiais, político ideológicas, religiosas, ético-comportamentais, econômicas ou geográfico-espaciais. Por isso, tem sido a referência essencial de diversas disciplinas e campos teóricos, de variados matizes filosóficos-ideológicos (De Paula, 2000: 15).

17 Haesbaert (1990) explica que a modernidade estabelece um movimento permanente de interação e substituição do antigo pelo novo, e marca a vivência conjunta de uma 
diversidade de transformações em diferentes tempos e intensidades que podem ser confrontadas em múltiplas escalas e contextos espaciais. Segundo Gomes (1996: 48), o fato moderno é marcado pelo "caráter de ruptura, a imposição do novo e a pretensão de alcançar a totalidade". Seu movimento permanente de negação da tradição e do passado conferem a sensação de progresso regular e consecutivo, que Berman (1986) caracterizará como um modo de experiência vital.

$\mathrm{Na}$ interface com a história, Carvalho (2008) afirma que

Qualquer definição de modernidade ocidental incluirá a ênfase na liberdade do indivíduo, em sua independência do Estado (cidadania) e da Igreja (secularismo), no espírito de iniciativa, no desejo de mudança ou progresso. 0 ambiente histórico que a gestou e que ela ajudou a gestar foi o do crescimento das cidades pós-medievais, da ciência, da indústria e da sociedade de mercado. (Carvalho, 2008: 25)

Da modernidade decorre a noção de modernização, que Habermas (2002) associa às ideias de revolução, progresso, emancipação, desenvolvimento, crise, entre outras, que exprimem o incontido desejo por extrair de si mesma sua normatividade, em clara negação a modelos antigos, como forma de se auto afirmar. Segundo Castilho (2011), a modernização incorpora em si tanto transformações nas bases técnicas da produção quanto transformações ideológicas. Expressa-se necessariamente nos lugares e promove conexões.

20 Soja (1993) enxerga a modernização como um processo de reestruturação da sociedade decorrente da dinâmica histórica e geográfica dos modos de produção, que se desenvolve no espaço de maneira desigual. Por natureza, é imprevisível tanto em sua gênese quanto em seus resultados, tem intensidade variável, pode implicar reformas ou revoluções, e geralmente desencadeia embates pelo controle do poder sobre as relações de socialização e de produção, manifestando-se nos mais variados contextos e escalas. Parte dos processos de reestruturação são, historicamente, conduzidos por elites econômicas e políticas. Um território - um país, por exemplo - dificilmente experimenta processos de modernização na sua estrutura produtiva sem a participação essencial do Estado.

\subsection{0 fator elite}

21 A elite ou as elites de uma região ou país podem ser pensadas como um fator capaz de impulsionar ou retardar processos de modernização. Em momentos históricos nos quais o povo está ausente das lutas sociais, as elites econômicas e políticas são determinantes como agentes de transformação de aparatos produtivos, sobretudo quando ocasionalmente se encontram unidas, perfiladas em objetivos mais ou menos consensuais.

22 As primeiras formulações acerca da existência de elites surgiram no século V a. C., a partir de uma crítica elaborada por Sócrates ao observar que, no momento em que homens comuns passaram a dirigir os negócios da cidade, a organização social pela vontade divina teria sido suplantada pelo surgimento da política e da democracia (Holanda, 2011). É a partir daí que, posteriormente, Platão identificaria em certos estratos da sociedade grega indivíduos capazes de serem condutores ideais das decisões políticas no interior da Polis (Saraiva, 2016).

23 Segundo Bottomore (1974), o termo "elite", propriamente, surge na França no século XVII como referência a produtos de alta qualidade. Posteriormente, no século XVIII, foi 
expandido para designar determinados grupos sociais que exerciam relações de superioridade no seio dos grupos. Ao final do século XIX e início do século XX, alguns pensadores elaboraram reflexões sistêmicas sobre o que denominaram de Teoria das Elites. Formulada inicialmente por Gaetano Mosca nos Elementi di Scienza Política (1896), a teoria foi aprimorada, em ordem cronológica, por Vilfredo Pareto, Robert Michaels e Wright Mills, cujo entendimento fundamental é de que em todas as sociedades havia, minimamente, um grupo de governantes e outro de governados.

Barnabé (1999) identifica que uma elite é formada por grupos de indivíduos que concentram poderio econômico, político e ideológico, e que compartilham o interesse comum pelo controle do poder local, ainda que, internamente, lidem com contradições (via de regra, há, no bojo dos grupos dominantes, elites e contra elites, definidas pelo momento político em vigor). De maneira complementar, Silva (2004) enumera critérios que são recorrentes na definição das elites, geralmente balizados pela distribuição desigual de bens, ou ainda, pelas diferentes intensidades em que se manifestam determinadas virtudes individuais. Assim, podem ser arrolados a propriedade de terras e riquezas, intelecto, carisma, poder e influência política, aspectos que em maior ou menor proporção seriam capazes de dar coesão às relações estabelecidas em uma determinada sociedade, bem como de determinar as formas de acesso aos lugares de poder.

Norberto Bobbio et al. (1998) propuseram, em seu Dicionário de Política, uma síntese dos elementos comuns à origem e à configuração das elites:

1) em toda sociedade organizada, as relações entre indivíduos ou grupos que a caracterizam são relações de desigualdades; 2) a causa principal da desigualdade está na distribuição desigual do poder, ou seja, no fato de que o poder tende a ficar concentrado nas mãos de um grupo restrito de pessoas; 3 ) entre as várias formas de poder, o mais determinante é o poder político; 4) aqueles que detêm o poder, especialmente o poder político, ou seja, a classe política propriamente dita, são sempre uma minoria; 5) uma das causas principais por que uma minoria consegue dominar um número bem maior de pessoas está no fato de que os membros da classe política, sendo poucos e tendo interesses comuns, têm ligames entre si e são solidários pelo menos na manutenção das regras do jogo, que permitem, ora a uns, ora a outros, o exercício alternativo do poder; 6) um regime se diferencia de outro na base do modo diferente como as Elites surgem, desenvolvem-se e decaem, na base da forma diferente como se organizam e na base da forma diferente com que exercem o poder; 7) o elemento oposto à Elite, ou à não-Elite, é a massa, a qual constitui o conjunto das pessoas que não têm poder, ou pelo menos não têm um poder politicamente relevante, são numericamente a maioria, não são organizadas, ou são organizadas por aqueles que participam do poder da classe dominante e estão portanto a serviço da classe dominante (a teoria da sociedade de massa é a contrapartida da teoria das Elites e ambas se desenvolveram neste último século paralelamente). (Bobbio et al., 1998: 391)

Codato (2015) propõe métodos de análise para identificação de posições de elite baseado em três aspectos que a definiriam: poder, influência e decisão. De maneira simples, o primeiro deles, denominado "método posicional", identifica como membros da elite aqueles indivíduos que ocupam posições formais de poder em uma determinada sociedade. O segundo, "método decisional", busca identificar indivíduos que, mesmo não estando em cargos formais, são capazes de decidir estrategicamente sobre temas de interesse social. O terceiro e último é chamado de "método reputacional", que identifica membros da elite em uma sociedade a partir da indicação, por especialistas, 
de um pequeno número de indivíduos presentes em uma ampla lista de lideranças préselecionadas.

Embora bastante discutido, Heinz (2006) alerta sobre a imprecisão permanente do conceito de elite, entre outros aspectos, conferido por seus determinantes subjetivos. Ainda assim, revela que há atualidade no debate das elites, e que é possível identificálas em diferentes escalas, bem como determinar sua articulação em redes em diferentes recortes espaço-temporais. À guisa do estudo que se desenvolve, é preciso estabelecer um prudente alerta: as elites se organizaram de maneira distinta nos diferentes momentos da história, possuem alta capacidade de perpetuação no poder (por meio de relações familiares), e isso é verificável em Minas e no Brasil - tanto nas características dos indivíduos, como em relação aos objetivos comuns. São, portanto, passíveis de comparação em face de seu caráter de minoria dirigente organizada, e a análise de sua atuação é relevante para o entendimento de processos de reestruturações territoriais. ${ }^{3}$

\subsection{0 fator urbano e urbano-industrial}

28 A compreensão da urbanização como processo perpassa a relação entre campo e cidade, aspecto central das sociedades humanas, cuja diferenciação geográfica tem forte nexo com a paulatina divisão do trabalho manual e intelectual (Monte-Mór, 2006). Segundo Monte-Mór (2006), o termo urbano - em desuso por séculos - voltou a ser utilizado no século XVI em referência à cidade-império e no século XVII em referência à cidade-sede do Império Britânico. Já a palavra cidade tem seu uso recuperado no século XIII, em referência à representação de poder emanadas por cidades bíblicas ou ideais, e depois passou a ser utilizada em referência às localidades dotadas de sedes episcopais, geralmente, caracterizadas por serem localidades centrais. Atualmente, compreende-se que as cidades são resultantes da intensificação massiva da divisão socioespacial do trabalho, pela intensificação das bases regulares de trocas baseadas tanto em cooperação quanto na competição, e pelo fluxo constante de bens e indivíduos, que caracterizam o processo de urbanização. É este processo que vai resultar na progressiva e irreversível perda do protagonismo do campo sobre a cidade no século XVIII, quando as cidades criaram condições de mercado capazes de alterar a lógica produtiva do campo.

O espaço urbano das cidades constitui-se, conforme Corrêa (1989), a partir da justaposição $0^{4}$ de diferentes usos da terra - comercial, industrial, residencial, entre outros -, que evidenciam o caráter difuso da urbanização. Para o autor, o espaço urbano é "fragmentado e articulado, reflexo e condicionante social, um conjunto de símbolos e campo de lutas. É assim a própria sociedade em uma de suas dimensões, aquela mais aparente, materializada nas formas espaciais" (Corrêa, 1989: 1). Os usos da terra a que Corrêa se refere são caracterizados por Singer (1976) como funções urbanas (como, por exemplo, a administração pública, a devoção religiosa e os serviços de instrução), que fornecem aos indivíduos do campo a contrapartida pela negociação de seus excedentes.

Via de regra, as cidades historicamente se organizam e se articulam em redes cuja hierarquia pode ser lida espacialmente. Tal qual organismos vivos, as cidades estão sujeitas a modificações estruturais capazes de alterar sua função e posição na articulação urbana, e podem ser mais ou menos susceptíveis à penetração de elementos de novas dinâmicas econômicas, o que é refletido em sua fisionomia e paisagem (Geiger, 1963). A industrialização foi um dos processos que provocou esse fenômeno 
mundialmente. A Revolução Industrial e sua criação - a indústria fabril - deram origem à urbanização tal qual conhecida na atualidade. Até meados do século XVII, poucas eram as cidades em que a concentração de mercado e/ou poder geravam processos de urbanização (Monte-Mór, 2006). O processo de industrialização fez surgir a cidade industrial, que se proliferou e modificou as relações de troca e poder, tendo como facilitador a revolução dos transportes operada pelo surgimento e expansão de ferrovias e de navios à vapor, que imprimiram uma nova lógica de produção do espaço.

De maneira sintética, a industrialização pode ser definida como um processo não espontâneo de transformação das bases de produção de uma sociedade, oriundo de uma vontade consciente de desenvolvimento, com modificações sensíveis na configuração das esferas políticas e sociais de decisão, cuja marca principal é a transição de uma economia baseada na agropecuária (setor primário) para outra fabril (setor secundário) (Bobbio, 1998). Segundo Dantas et al. (2013: 21), a indústria "é definida pelo grupo de empresas voltadas para a produção de mercadorias que são substitutas próximas entre si e, dessa forma, fornecidas a um mesmo mercado"; por sua vez, o mercado a que se refere é caracterizado como "demanda por um grupo de produtos substitutos próximos entre si".

Em escala global, a industrialização tem como marco histórico a Revolução Industrial Inglesa do século XVIII, cujos reflexos foram imediatos no resto do mundo, sobretudo nas nações de maior desenvolvimento que dali importaram um novo modelo econômico. O momento marca a substituição da produção manufatureira pela maquinofatureira, que caracteriza a transição do capitalismo comercial para o industrial. As fábricas - genericamente definidas como prédios ou instalações onde um conjunto de indivíduos e máquinas realizam a transformação de matérias-primas em mercadorias de alto valor agregado com a maior eficiência possível - foram uma inovação chave e, no entanto, controversa: ao mesmo tempo em que deu origem a modelos inéditos de produtividade, disseminou novas formas de exploração da mão-deobra.

Tais definições revelam a importância de não se perder de vista questões relacionadas à escala. Fábricas podem ser instalações com pessoal e maquinário que podem variar da unidade ao milhar, bem como a indústria pode ser definida por um pequeno conjunto de estabelecimentos fabris primitivos quanto por grandes parques industriais de alta tecnologia. Em outras palavras, os conceitos revelam níveis de complexidade espaçotemporais que suscitam o aposto sociedade "urbano-industrial".

\section{A peculiar trajetória mineira rumo à modernização}

Desde o século XVIII desenhou-se em Minas Gerais um conjunto de reestruturações capazes de evidenciar seu protagonismo na formação do Brasil moderno. ${ }^{5}$ Ao longo de sua história, revelaram-se processos que apenas poderiam se deflagrar por suas excepcionalidades geo-históricas, sobretudo nos diferentes contextos políticos que enfrentou em sua trajetória. Sua diversidade mineral, em que se destacam, além do ouro e do ferro, suas grandes extensões de solos férteis, deu o tom para a ocupação e formação de sua rede de cidades. Com efeito, a paisagem da mineração era composta por um mosaico em que se mesclavam a exploração do ouro e o cultivo de gêneros de primeira necessidade (Wirth, 1982; Moraes, 2007; Meneses, 2007; Carrara, 2007; Almeida, 2010). A enormidade de riquezas que circularam por seu território viabilizou o 
surgimento de uma elite letrada e influente que se metamorfoseou ao longo dos séculos e que, apesar de suas inúmeras discordâncias internas, foi capaz de manter a unidade territorial mineira. $\mathrm{O}$ conjunto de obras analisadas permitiu revelar algo que parecia pairar, sem, contudo, aterrissar: a busca pela modernidade foi a linha que costurou as reestruturações territoriais de Minas.

O entendimento do perfil urbano-industrial de Minas no início do século XXI só pode ser interpretado corretamente se forem consideradas as atuações de suas elites letradas que buscaram desenvolver no estado paisagens de modernidade semelhantes às europeias. Desde o século XVIII, os homens ricos de Minas compreendiam que a aproximação com as letras seria o meio ideal de ascensão social e participação na vida política. Parte da primeira elite letrada mineira era filha desses homens. Ao estudarem na Europa, trouxeram consigo ideias de modernização como possibilidade, propiciada pelas vivências em prósperas cidades europeias que favorecia o contato com os ideais iluministas; com as ciências naturais; com a racionalidade na ocupação territorial; com ideias de reformas urbanas; com as experiências de liberdade (como a dos Estados Unidos, muito comentada à época); e, posteriormente, com o positivismo, a república e a democracia, entre tantas outras experiências (Barretto \& Paim, 1989; Boschi, 1991; Villalta, 2007).

Todavia, o que era fluido no pensamento norte-ocidental tornava-se viscoso no teatro político ao sul do equador. Para além das letras, foi o desenvolvimento de uma forma relativamente coesa de se fazer política entre as elites mineiras que viabilizou que Minas Gerais mantivesse-se sempre como uma das três mais relevantes economias do território brasileiro. Os aspectos que comprovam esta afirmação serão passados em revista.

\subsection{Século XVIII: a modernização precoce irradiada pela região central de Minas Gerais}

37 No século XVIII, a exploração de metais preciosos propiciou o surgimento de uma economia diversificada entrelaçada a uma rede de povoações de alta capilaridade. Nas principais vilas, as marcas da modernidade estavam presentes em sua paisagem, na arquitetura caracteristicamente portuguesa, nas estratégias de ordenamento urbano e nas sofisticadas mercadorias e vestuário importados, algo sem precedentes em territórios portugueses que distavam 400 quilômetros da costa atlântica (Rodrigues, 1986; Monte-Mór, 2001; Rodarte, 2004; Lemos et al., 2006; Carrara, 2007; Moraes, 2007; De Paula, 2007; Fonseca 2012; Santos, 2015).

O rápido crescimento demográfico e a diversidade da população que afluía para a região da Minas contribuiu para a difusão de informações e ideias, muitas das quais subversivas, que acarretaram a formação de uma cultura urbana rebelde e na mudança do perfil dos já recorrentes atos de sedição. Além disso, fortalecia-se uma elite urbana esclarecida, cônscia dos percalços da condição colonial do território e do atraso de Portugal em relação aos países em processo de industrialização, tais como Inglaterra e França. A noção das capacidades de autossuficiência da capitania, o desejo pela liberdade e o senso de emancipação pela industrialização ganharam força após a "Viradeira" em Portugal e culminaram no movimento da Inconfidência Mineira. Embora tenha fracassado, desenhou-se, entre os mineiros, uma moderna consciência de nação que teria influência em outras sedições pela Colônia e na declaração de 
independência em 1822. Os ideais progressistas dos inconfidentes mineiros adentraram no século XIX e foram aclamados, após a independência, nos mais variados circuitos republicanos que se espalharam pelo território (Novais, 1981; Dias, 1985; Wehling, 1986; Barretto \& Paim, 1989; Maxwell, 1989; Anastasia, 1998; Gonçalves, 2001; Focas, 2002; Figueiredo, 2005; Carvalho, 2005; Carvalho, 2008; Viscardi, 2013; Moreira, 2013; Furtado, 2014; Figueiredo, 2016).

Geograficamente, a região central de Minas viabilizou, por sua condição mineral e enorme capacidade de atração populacional nos Setecentos, a interiorização dos caminhos do Brasil. Da região central, seguiam aventureiros pelo caminho de Goiás em busca de novas oportunidades, o que marca o início da conquista do oeste brasileiro. Por sua vez, a necessidade de proteção das riquezas e o combate aos descaminhos do ouro fortaleceram a posição do Rio de Janeiro que, por causa disso, se tornou capital em 1763. Os laços do Norte de Minas com a Bahia foram mantidos pela hidrovia do rio São Francisco e pelo caminho dos currais, e a região sul se dinamizava como centro abastecedor de alimentos da região central e de São Paulo. Com efeito, formaram-se cidades especializadas na produção de bens de consumo, cujo desempenho econômico na segunda metade do século XVIII gerava ganhos comparáveis aos das cidades mineradoras. Consolidou-se uma hierarquia urbana mineira nos Setecentos cujos traços permaneceriam até a segunda metade do XIX (Geiger, 1963; Libby, 1988;1989; Maxwell, 1989; Monte-Mór, 2001; Costa, 2007; De Paula, 2007; Cunha, 2007; Matos et al., 2007; Andrade, 2010; Fonseca, 2011; Fonseca, 2012; Matos, 2012; Valle et al., 2014).

O escasseamento do ouro de aluvião e de encostas inviabilizou a prática do garimpo e provocou mudança no perfil da exploração, que passou a ser subterrânea e capitaneada por companhias inglesas, que possuíam o capital e a tecnologia para tanto. 0 consequente arrefecimento das economias urbanas da região mineradora central, por sua vez, fez com que uma parcela da população a abandonasse e buscasse áreas de terras férteis e agriculturáveis. A produção de gêneros alimentícios e o comércio, que já eram relevantes na pauta econômica mineira (mais da metade dos homens ricos não tinham a mineração como ocupação principal), deixou de ser ofuscada pela extração aurífera e passou a figurar como principal economia da capitania. Logo, transmutaramse as elites e as formas de se fazer política. As Minas, até então caracterizadas pelas liberdades e conflitos ligados ao ouro, passam à tradição e à estabilidade da terra (Lanna, 1986; Libby, 1988; Lenharo, 1993; Queiroz \& Braga, 1999; Carvalho, 2005; Meneses, 2007; Carrara, 2007; Godoy, 2009).

\subsection{Século XIX: a articulação das elites mineiras em prol do projeto industrializador de Minas Gerais}

41 No século XIX, o mundo assistiu à difusão da primeira Revolução Industrial, cuja invenção da máquina à vapor e seus incontáveis desdobramentos fizeram diminuir os tempos de deslocamento e proporcionaram novas formas de produção e consumo. Em Minas Gerais as condições físicas e a presença de recursos naturais ainda eram determinantes para a localização dos núcleos de produção, bem como da sua rede de caminhos. Tais características revelavam-se em uma grande diversidade interna, com sistemas econômicos regionais de autonomia variável e que dificilmente se conectavam, característica que levou ao brasilianista John Wirth (1982) a denominar a província de “mosaico mineiro". o caráter insular da província exigia que vários de seus núcleos 
populacionais fossem autossuficientes, mesmo porque as grandes distâncias e a qualidade dos acessos seriam fatores gravosos em situações de escassez local (Wirth, 1982; Martins, 1980; Lanna, 1986; Libby 1988, 1989; Slenes, 1988; Pires, 2004; Lenharo, 1993; Paiva, 1996; Rodarte, 1999).

Os diferentes núcleos sobreviveram e prosperaram em razão de um conjunto de particularidades que nem sempre coincidiam, entre as quais suas características urbanas, a oferta de uma gama de serviços especializados, a eficiente produção de bens de consumo, a presença de alguma indústria de transformação, ou sua localização em entroncamentos de grande circulação e comércio. Muitas áreas, por outro lado, permaneceram inabitadas ao longo dos Oitocentos e algumas até a primeira metade do século XX por dificuldades das mais diversas, como a distância dos maiores centros, a inviabilidade de escoamento de produção, o intricado manejo do solo, ou os conflitos com as populações nativas, entre outras, mesmo que existissem incentivos do governo provincial para a sua ocupação e desenvolvimento. Esse conjunto de fatores justificam o fato de as áreas de maior dinamização serem justamente aquelas próximas aos centros mais desenvolvidos do Império, como as regiões Sul e Mata, cujas relações comerciais suscitaram, inclusive, movimentos separatistas e de anexação pelas províncias de Rio e São Paulo, sem lograr sucesso (Rodarte, 2008; Godoy, 2009; Cosentino, 2013; Dulci, 2013; Graça-Filho, 2013).

Nos Oitocentos, Minas Gerais apresentou desenvolvimento econômico e se manteve integrada à economia nacional, principalmente, pela produção de alimentos e de mercadorias com algum nível de transformação. Por ter a maior população do Império, possuía também o maior colégio eleitoral e, por consequência, a maior bancada na câmara dos deputados. A bancada mineira, embora representasse as elites da terra, não era contrária às ideias de progresso via industrialização, porquanto era composta por deputados em geral letrados e egressos de educandários como a Universidade de Coimbra, o Colégio do Caraça e, ao final dos Dezenove, a Escola de Minas de Ouro Preto, entre outros liceus de menor vulto que também formavam quadros políticos para a atuação local. A circulação de centenas de jornais e a formação de partidos progressistas faziam difundir, entre outros, as vantagens da criação de indústrias (artesanais), que alimentavam os debates provinciais e nacionais. A chegada da geração Gorceix à vida política, já no último quartel dos Dezenove, intensificou o debate em prol do desenvolvimento e do progresso (Rodrigues, 1986; Carvalho, 2005; Barbosa, 2009; Matos \& Mello, 2012; Carvalho, 2013; Viscardi, 2013; Moreira, 2013).

Para além da agitação política e da crescente massa de letrados, assistiu-se no território mineiro iniciativas de expressiva modernidade e com inequívoco pioneirismo. $\mathrm{Na}$ contramão do perfil econômico agrário que se formou em Minas, alguns empreendedores trouxeram para o território parte das primeiras experiências fabris siderúrgicas e têxteis do país, a primeira usina de energia hidrelétrica e a maior rede ferroviária do Brasil. Tratam-se de empreendimentos heroicos e ousados, na medida em que faltava à gestão nacional maiores definições sobre as políticas territoriais, fiscais, de incentivos, créditos e proteção aduaneira, ausências que afastavam boa parte de potenciais investidores. Mesmo a questão do fim da escravidão, cujas vantagens já eram evidentes no mundo capitalista moderno, levou mais de 50 anos para ser resolvida. As realizações desses empreendedores e suas fábricas tiveram profundo impacto no campo das representações, sobretudo pelo exemplo de que outras perspectivas de desenvolvimento econômico eram não só possíveis como viáveis, uma vez que as crises 
de superprodução na cafeicultura começavam a preocupar os governos (Vaz, 1977; Wirth, 1982; Libby, 1988; De Paula, 2000; De Paula, 2006; Rodarte, 2008; Godoy \& Barbosa, 2008; Baeta et al., 2012; Mello, 2010; Batista et al., 2012; Cosentino, 2013; Dulci 1999, 2013; Lima; 2015).

Ao final dos Oitocentos o Brasil buscou desenvolver uma política concreta para atração e fixação de imigrantes, com a expectativa de suprir o hiato deixado no campo pelo fim da escravidão e, ao mesmo tempo, induzir a formação de uma cultura industrial. Embora tenha sido tardia, a relevante massa de migrantes contribuiu diretamente para o desenvolvimento de algumas regiões brasileiras, como as do Sul, São Paulo e a Zona da Mata mineira, que se tornou um caso exemplar. A fixação de mão de obra europeia que ali chegou empregada na construção de estradas de ferro foi primaz para a formação de uma classe assalariada urbana e livre. São relevantes as experiências modernas assistidas em Juiz de Fora - que se tornou a primeira cidade industrial de Minas Gerais ("A Manchester Mineira") - tais como a instalação de diversas fábricas, bancos, sistema de bondes, fornecimento de energia hidrelétrica, entre outros, viabilizados diretamente pelo ambiente propício aos investimentos, sobretudo pelo novo perfil de consumo que se firmava e indiretamente pela presença maciça de capitais oriundos da cafeicultura regional (Singer, 1974; Lamounier, 2000; Pires, 2004; De Paula, 2006; Saraiva, 2008; Dulci, 2013; Lamounier, 2013).

As experiências da Zona da Mata não foram compartilhadas pelas demais regiões mineiras, nas quais permanecia o desenvolvimento desigual e declinante. A exceção era a região central, que, com base no projeto de recuperação a partir de investimentos em prol da nova capital, concentrou a maior parte dos empreendimentos de caráter industrial no início do século XX. Outra exceção foi a região Sul, que desenvolveu uma sofisticada dinâmica produtiva para o abastecimento de Rio e São Paulo, cuja economia cafeeira, em sucedâneo à declinante cafeicultura da Zona da Mata, desenvolvia-se a passos largos (Lima, 1977; Diniz, 1981; Lanna, 1986; Negri, 1996; Queiroz \& Braga, 1999; Cano, 2002; De Paula, 2006; Borges, 2011).

Apesar de tais experiências, é inegável que a maior parte do extenso território mineiro permaneceu agrário e de baixo desenvolvimento. Os empreendimentos de maior vulto concentraram-se primeiramente na região central e depois ganharam força nas regiões Sul e Mata, onde o notável desenvolvimento urbano-industrial de Juiz de Fora a transformara em uma cidade efetivamente capitalista pioneira na província. A quantidade de riquezas geradas nas duas últimas regiões, associada à insatisfação com o governo provincial, foi motivo gerador de movimentos separatistas que, embora não lograssem êxito, revelavam a fragilidade da coesão regional do mosaico mineiro (MataMachado, 1987; Aguiar, 2006; De Paula, 2006; Barbosa, 2009; Matos e Mello, 2012; Dulci, 2013).

\subsection{Século XX: recuperação econômica e consolidação da primazia do espaço urbano industrial em Minas Gerais}

O quadro econômico em fins do século XIX revelava a clara fragilidade territorial da província, cuja capital há tempos vinha perdendo prestígio e capacidade de polarizar os interesses dos mineiros. $O$ advento da república e da federação acenavam para novas possibilidades, como a ideia de retomar as rédeas do desenvolvimento de Minas. Assim, no Congresso Constituinte Mineiro de 1891 deliberou-se pela transferência da capital e 
criação de um projeto urbano arrojado que colocasse o novo estado em sintonia com os centros mais prósperos da época e que fosse capaz de atrair a atenção dos investidores estrangeiros. A construção e inauguração da moderna Belo Horizonte, em 1897, e a realização do Congresso Agrícola, Comercial e Industrial de Minas Gerais, em 1903, foram norteadores de políticas que direcionariam o desenvolvimento mineiro no século XX (Singer, 1974; Schmidt, 1979; Mata-Machado, 1987; Matos, 1992; Dulci, 1999; De Paula, 2000; Carvalho, 2005; Aguiar, 2006; Saraiva, 2008; Barbosa, 2009; Matos \& Mello, 2012).

49 Ao longo da primeira metade do século XX, a despeito das enormes dificuldades de superar o atraso em relação a Rio de Janeiro e São Paulo, Minas Gerais seguiu uma pauta desenvolvimentista: investiu na implantação de indústrias de base, buscou desenvolver um sistema viário articulado, e formou um corpo técnico para auxiliar nos processos de tomada de decisão. A indústria siderúrgica desenvolvia-se a passos largos sob os cuidados de uma nova elite ansiosa em romper com o perfil agrário do estado. (Diniz, 1981; Crocco, 1996; Dulci, 1999; Queiroz \& Braga, 1999; Cano, 1997;2002; Diniz \& Azzoni, 2002; Barbosa, 2009; Matos, 2012).

50 A guinada aconteceu na segunda metade do século $\mathrm{XX}$, quando o processo de desconcentração industrial paulista, a metropolização de Belo Horizonte e a transferência da capital para Brasília favoreceram Minas Gerais como espaço econômico para os interesses do capital internacional. Ainda que tardiamente, Minas passaria então por um forte processo de modernização, cujas mudanças foram percebidas em suas centralidades históricas. Muito contribuiu a tradição desenvolvimentista mineira, por exemplo, nos governos de Benedito Valadares (1933-1945), que priorizou a atuação do setor público em prol do desenvolvimento econômico regional; e de Juscelino Kubitschek (1951-1955), que provocou o fim do mosaico mineiro, quando concretizou o "Binômio: Energia e Transporte", que fez diluir as separações regionais a partir da integração de territórios longínquos e reforçou a polaridade que Belo Horizonte adquire na segunda metade do século XX. Por consequência, ocorre também a diminuição dos rompantes independentistas que eram abundantes ao final do século XIX (Diniz, 1981; Crocco, 1996; Dulci, 1999; Queiroz \& Braga, 1999; Cano, 1997;2002; Diniz \& Azzoni, 2002; Barbosa, 2009; Matos, 2012).

51 A concentração urbana e econômica e a modernização da indústria mineira apresentavam nexos claros. Os municípios - em especial os que representavam centralidades - que foram beneficiados por intervenções estruturais estatais planejadas, ou que foram capazes criar autonomamente as bases para a sua própria industrialização, revelaram-se como atratores de investidores e de trabalhadores, e por consequência desenvolveram um setor terciário vigoroso. Aliás, as mudanças modernizadoras provocaram polarizações decorrentes dos processos de reestruturação permitiram que cidades se tornassem importantes centros comerciais, capazes de atrair população e centralizar serviços de toda ordem. O crescimento de São Paulo, a fundação de Brasília, a criação do parque siderúrgico do Vale do Aço e a metropolização de Belo Horizonte foram os principais balizadores dessas polarizações (Diniz \& Crocco, 1996; Azzoni, 2002; Queiroz \& Braga, 1999; Costa, 2015).

52 O sonhado processo de recuperação econômica aconteceu. A produção industrial superou a agropecuária, desvinculou o destino de muitos municípios de sua histórica vocação e promoveu na segunda metade do século XX um estado de forte articulação 
econômica e rede urbana coesa, mais ou menos como almejavam as elites do final do século XIX.

\section{Considerações finais}

53 Grandes processos de modernização não ocorrem sem a participação do Estado. Mas a modernização incipiente, inicial, que aconteceu em Minas Gerais no século XVIII, não foi deflagrada pela Coroa Portuguesa, mas sim por setores da elite que, ao instruírem-se em Portugal, tiveram contato com as ideias do iluminismo (independência, república, progresso, industrialização). São numerosos os exemplos em que indivíduos notáveis se anteciparam às ações do Estado, tais como Wilhelm Eschwege, João Monlevade, Bernardo Mascarenhas, entre outros. Quando o país conquistou a sua independência e o estado progressivamente se fortaleceu, foi possível, ainda que modestamente, a instalação de infraestruturas produtivas que auxiliaram o desenvolvimento econômico. Estruturas, aliás, que a iniciativa privada era incapaz criar à época. Mais tarde, o Brasil da Era Vargas cria as condições para o surgimento de uma burguesia industrial consistente.

$\mathrm{Na}$ narrativa-síntese apresentada foram focalizadas as modernizações que Minas assistiu, várias delas com desdobramentos econômicos e territoriais nos quais o urbano em mudança destaca-se século XVIII e depois, no século XX, a partir da afirmação do capitalismo industrial e do protagonismo da moderna Belo Horizonte. As evidências de que houve um processo de modernização e reestruturação econômica sustentam-se pela passagem, em poucas décadas, da primazia dos setores extrativista e agroexportador para o setor industrial de proeminência nacional.

Frações da elite foram extremamente relevantes no processo de desenvolvimento de Minas Gerais. Sabidamente, as elites não eram homogêneas, mas aquelas que mais se destacaram em defesa da ideia de progresso também eram as mais escolarizadas. No passado, vale a pena frisar, vários dos integrantes da elite política eram certamente muito mais bem preparados, idôneos e dedicadas a um projeto de desenvolvimento nacional do que mais tarde os governantes de Minas se mostraram. Essas elites foram desaparecendo, provavelmente porque, entre outras razões, migraram para centros políticos e econômicos mais dinâmicos e sucumbiram ao ideal neoliberal imposto pela globalização. Diante dessas circunstâncias, nos últimos 40 anos, o estado foi administrado por diversos políticos inexpressivos, despreparados, pouco instruídos e até mesmo corruptos.

56 Toda maneira, convém observar que, desde o início da ocupação portuguesa a região das minas se mostrou de difícil exploração e seus recursos naturais (notadamente os minerais preciosos), como mostrado anteriormente, é que a tornaram não só populosa, mas também uma importante unidade colonial no século XVIII. Aos recursos abundantes e atraentes, como a madeira, a água e ouro, foi agregado no início do século XIX um outro recurso estratégico de desenvolvimento, o minério de ferro, explorado por mineradoras inglesas e por pequenas fundições nacionais, que ao longo de dois séculos se consolidaram na grande siderurgia mineira.

57 Ao longo do século XX, Minas permanece extraindo minério de ferro e passou a produzir de ferro gusa a aço, além de derivados metalúrgicos e siderúrgicos mais complexos em escala industrial. Tudo isso articulado pela Estrada de Ferro Vitória à Minas (EFVM). Solidificou-se na região central mineira um complexo exportador de 
commodities com grande densidade de capitais e intensa capacidade de explorar/extrair os recursos minerários. Convém observar que a cadeia produtiva da mineração, que envolve mina, ferrovia e porto, ganhou visibilidade internacional ainda quando tinha o nome de Companhia Vale do Rio Doce. Ao ser privatizada, seu crescimento foi globalmente desmesurado, o que a tornou inalcançável do ponto de vista de controle e fiscalização governamental. o cenário econômico favorável à mineração do início no século XXI fez com que as demais mineradoras passassem a mimetizar o modus operandi da Vale, o que contribuiu decisivamente para a ocorrência de grandes desastres tecnológicos como os de Herculano em Itabirito (2014), da Samarco em Mariana (2015) e da Vale em Brumadinho (2019).

Do ponto de vista territorial, o mosaico mineiro se fez presente durante boa parte de sua história. Minas era composta por enclaves territoriais pertencentes a potentados donos de terras e homens. As cidades se mantinham praticamente independentes umas das outras com um comércio pouco vigoroso. Os processos de integração territorial pulverizaram essas relações personalistas e dissolveram esse mosaico em uma grande unidade territorial coesa. Isso foi feito às custas de investimentos governamentais e atividades econômicas de grande porte. Juscelino Kubitschek foi um dos protagonistas dessas mudanças quando governador em 1950, que consolidou o projeto de integração de Minas proposto por João Pinheiro em 1903. Como presidente do Brasil, JK deu continuidade a essas metas, promoveu grandes reestruturações territoriais, e favoreceu significativamente o estado mineiro.

No século XX, o processo de urbanização alcançou outra grandeza em Minas Gerais. Havia uma espécie de compreensão entre as elites mineiras de que a industrialização beneficiaria a todos e, por isso, os arautos do progresso e da modernização tiveram suas ações expandidas. Um dos resultados desse processo foi a concentração urbana em favor de uma metrópole. Posteriormente, após a sua consolidação nos anos de 1970, verificou-se um processo de saturação e desconcentração espacial. Por consequência, houve a interiorização da urbanização no estado que fez emergir cidades médias, atores centrais do processo de integração territorial contemporâneo.

Assim, o urbano assume o protagonismo sobre o rural em Minas nos últimos 40 anos. Atualmente, essa urbanização já não tem a mesma característica da urbanização do início do século, que era revestida dos efeitos da industrialização. A indústria continuou tendo um papel relevante, mas se afastou das cidades em razão da grande dimensão das novas plantas industriais. Nesse momento, em que há industrialização, mas não como um fator engastado no processo de urbanização, é o setor de comércio e serviços que ganha maior desenvoltura nas cidades mineiras. Não é demais reforçar: a concentração urbano-econômica mineira do século XXI é oriunda de uma tradição mineira desenvolvimentista, cujas origens remontam ao ideário de liberdade e progresso dos inconfidentes. 


\section{BIBLIOGRAFIA}

Abreu, Maurício de Almeida (1998). “Sobre a memória das cidades”. Território, Rio de Janeiro, v. 1, n. 4, pp.4-26.

Abreu, Maurício de Almeida (2000). "Construindo uma geografia do passado: Rio de Janeiro, cidade portuária, século XVII”. GEOUSP, São Paulo, v. 1, n. 7, pp. 13-25.

Aguiar, Tito Flavio Rodrigues de (2006). Vastos subúrbios da nova capital: formação do espaço urbano na primeira periferia de Belo Horizonte. 2006. 443 p. Tese (Doutorado) - Programa de Pósgraduação em História da Faculdade de Filosofia e Ciências Humanas, Universidade Federal de Minas Gerais, Belo Horizonte.

Almeida, Carla Maria Carvalho de (2010). Ricos e pobres em Minas Gerais: produção e hierarquização social no mundo colonial, 1750-1822. Belo Horizonte: Argvmentvm.

Anastasia, Carla Maria Junho (1998). Vassalos rebeldes: violência coletiva nas Minas na primeira metade do século XVIII. Belo Horizonte: Editora C/Arte.

Andrade, Leandro Braga de (2010). “A formação econômica de Minas Gerais e a perspectiva regional: encontros e desencontros da historiografia sobre os séculos XVIII e XIX". Caderno Caminhos da História (Universidade Severino Sombra), v. 6, pp. 1-19.

Azzoni, Carlos Roberto. “Sobre a necessidade da política regional”. In: Kon, Anita Org.). Unidade e fragmentação: a questão regional no Brasil. São Paulo: Perspectiva, 2002. pp. 17-43

Baeta, Alenice; Piló, Henrique; Neves, Marcus Duque (2012). “A Usina Wigg e a Siderurgia em Escala Industrial nas Minas Oitocentista. Ouro Preto, Minas Gerais-Brasil”. In: Colóquio Latino Americano Recuperação e Preservação do Patrimônio Industrial, 6., 2012, São Paulo. Anais... São Paulo: TICCIH, v. 1.

Barbosa, Daniel Henrique Diniz (2009). “Desenvolvimento econômico e pensamento desenvolvimentista: o caso de Minas Gerais (1933-1968)”. In: Encontro de Pós-Graduandos da FFLCH/USP, 4., 2009, São Paulo. Anais.... São Paulo: Universidade de São Paulo, v. 1.

Barnabé, Israel Roberto (1999). “Elite, Classe Social e Poder Local”. Estudos de Sociologia (São Paulo), Unesp/Araraquara, v. 1, n.7, pp. 103-118, 1999.

Barretto, Vicente; PAIM, Antônio (1989). Evolução do pensamento político brasileiro. Belo Horizonte: Itatiaia.

Batista, Felipe Alvarenga; Barbosa, Lidiany Silva; Godoy, Marcelo Magalhães (2012). "Transportes, modernização e formação regional-Subsídios a história da era ferroviária em Minas Gerais, 1870-1940". Revista de História Regional, Ponta Grossa, v. 17, n. 1, pp. 162-203.

Berman, Marshall (1986). Tudo que é sólido se desmancha no ar. São Paulo: Companhia das Letras.

Bobbio, Norberto; Matteucci, Nicola; Pasquino, Gianfranco (1988). Dicionário de política. Trad. Carmen C, Varriale et al. 11ª ed. Brasília: Editora Universidade de Brasília.

Borges, Barsanufo Gomides (2011). “Ferrovia e modernidade”. Revista UFG, Goiás, v. 13, n. 11, pp. 27-36.

Boschi, Caio César. "A Universidade de Coimbra e a formação intelectual das elites mineiras coloniais”. In: Centenário da Universidade de Coimbra, 7., 1991, Coimbra. Actas do congresso História da Universidade. Coimbra/Portugal: Universidade de Coimbra, 1990. v. 5. pp. 133-150. 
Bottomore, Thomas Burton (1974). As elites e a sociedade. Tradução de Otávio Guilherme C. A. Velho. $2^{\mathrm{a}}$ Ed., Zahar editores: Rio de Janeiro.

Cano, Wilson (1997). “Concentração e desconcentração econômica regional no Brasil: 1970/95”. Economia e sociedade, Campinas, v. 8, pp. 101-141.

Cano, Wilson (2002). Ensaios sobre a formação econômica regional do Brasil. Campinas: Editora da Unicamp.

Carneiro, Patrício Aureliano Silva (2013). Do sertão ao território das Minas Gerais: entradas e bandeiras, política territorial e formação espacial no período colonial. 2013. $407 \mathrm{f}$. Tese (Doutorado) - Curso de Geografia, Universidade Federal de Minas Gerais, Belo Horizonte.

Carneiro, Patrício Aureliano Silva; Matos, Ralfo Edmundo da Silva (2012). "Encontros e Desencontros entre Geografia e História e Tendências na Geografia Histórica Anglo-Saxã”. Espaço Aberto, Rio de Janeiro, v. 2, n. 2, pp.33-50.

Carrara, Ângelo Alves (2007). Minas e currais: produção rural e mercado interno em Minas Gerais, 1674-1807. Juiz de Fora: Editora da UFJF.

Carvalho, José Murilo de (2008). “Trajetórias republicanas”. Revista do Arquivo Público Mineiro, v. XLIV, pp. 22-35.

Carvalho, José Murilo de (2008). A construção da ordem: a elite política imperial. Teatro de sombras: a política imperial. 4a Edição. Rio de Janeiro: Civilização Brasileira.

Carvalho, José Murilo de. “Ouro, Terra e Ferro - Vozes de Minas”. In: Gomes, Ângela de Castro (Org.). Minas e os fundamentos do Brasil moderno. 1ed. Belo Horizonte: UFMG, 2005, v. 1, pp. 55-78.

Carvalho. José Murilo de. “A Escola de Minas de Ouro Preto”. In: RESENDE, Maria Efigênia Lage de; Villalta, Luiz Carlos (Org.). História de Minas Gerais: a província de Minas, v. 2. Belo Horizonte: Autêntica Editora; Companhia do Tempo, 2013. 444 p.

Castilho, Denis (2011). “Os sentidos da modernização”. Boletim Goiano de Geografia (Online), v. 30, pp. $125-140$.

Codato, Adriano. "Metodologias para a identificação de elites: três exemplos clássicos". In: Perissinotto, Renato M.; Codato, Adriano. (Org.). Como estudar elites. 1ed. Curitiba: Ed. UFPR, 2015, pp. 15-30.

Corrêa, Roberto Lobato (2016). "O interesse do geógrafo pelo tempo". Boletim Paulista de Geografia, v. 94, pp. 1-11.

Corrêa, Roberto Lobato et al (1989). O espaço urbano. São Paulo: Ática.

Cosentino, Daniel do Val (2014). “A economia mineira no século XIX e a transição do trabalho escravo para o trabalho livre”. Revista Debate Econômico, Alfenas, v. 1, n. 2, pp. 28-53.

Costa, Alfredo (2015). "Estruturas territoriais dinâmicas e mudanças modernizadoras ao longo de 70 anos em Minas Gerais (1940 - 2010)”. Revista da ANPEGE, v. 11, pp. 151-183.

Costa, Alfredo (2018). Modernização e reestruturações territoriais em Minas Gerais. 2018. 199f. Tese (Doutorado em Geografia) - Programa de Pós-Graduação em Geografia, Universidade Federal deMinas Gerais, Belo Horizonte.

Dantas, Alexis; Kertsnetzky, Jacques; Prochnik, Victor. "Empresa, Indústria e Mercados”. In: Kupfer, David; Hasenglever, Lia. Economia industrial: fundamentos teóricos e práticos no Brasil. 2. ed. Rio de Janeiro: Elsevier, 2013. pp. 15-24. 
De Paula, João Antônio (2000). Raízes da modernidade em Minas Gerais. 1ª ed. Belo Horizonte: Editora Autêntica.

De Paula, João Antônio. “A mineração de ouro em Minas Gerais no século XVIII”. In: Resende, Maria Efigênia Lage de; Villalta, Luiz Carlos (Org.). História de Minas Gerais - as Minas Setecentistas. Belo Horizonte: Autêntica/Companhia do Tempo, 2007, v. 1, pp. 279-301.

De Paula, Ricardo Zimbrão Affonso (2006). E do Caminho Novo das Minas dos Matos Gerais emerge a "Manchester Mineira" que se transformou num "baú de ossos" - História de Juiz de Fora: da vanguarda de Minas Gerais à “industrialização periférica”. 2006. 426 p. Tese (Doutorado) - Instituto de Economia, Universidade Estadual de Campinas, Campinas.

Dias, Fernando Correa (1985). “Mineiridade: construção e significado atual”. Revista Ciência \& Trópico, Recife, v. 13, pp. 73-89.

Diniz, Clélio Campolina (1981). Estado e capital estrangeiro na industrialização mineira. Belo Horizonte: UFMG/PROED.

Diniz, Clélio Campolina (1996); Crocco, Marco Aurélio. "Reestruturação econômica e impacto regional: o novo mapa da indústria brasileira". Nova economia, Belo Horizonte, v. 6, n. 1, pp. 77-103.

Dulci, Otávio Soares (1999). Política e recuperação econômica em Minas Gerais. Belo Horizonte: UFMG.

Dulci, Otávio Soares. “A indústria mineira no século XIX”. In: Resende, Maria Efigênia Lage de; Villalta, Luiz Carlos (Org.). História de Minas Gerais: a província de Minas, v. 1. Belo Horizonte: Autêntica Editora; Companhia do Tempo, 2013. Pp.347-372

Figueiredo, Luciano Raposo de Almeida (2005). Rebeliões no Brasil colônia. Rio de Janeiro: Zahar.

Figueiredo, Luciano Raposo de Almeida et al.. Impressões Rebeldes: documentos e palavras que forjaram a história do protesto no Brasil. 2016; Tema: Documentos históricos das revoltas no Brasil colônia (Site). [Disponível em < http://www.historia.uff.br/impressoesrebeldes/? page_id=4>. Acesso em $23 \mathrm{de}$ fev. de 2018].

Focas, Júlia Diniz (2002). Inconfidência Mineira: a história dos sentidos de uma história. Belo Horizonte: Faculdade de Letras da UFMG.

Fonseca, Cláudia Damasceno (2011). Arraiais e vilas d'el Rei - Espaço e poder nas Minas setecentistas. Belo Horizonte: Editora UFMG.

Fonseca, Cláudia Damasceno (2017). "Urbs e civitas: a formação dos espaços e territórios urbanos nas minas setecentistas”. Anais do museu paulista, São Paulo, v. 20, n. 1, pp. 77-108.

Furtado, João Pinto. "Inconfidências e conjurações no Brasil - notas para um debate historiográfico em torno dos movimentos do último quartel do século XVIII”. In: Fragoso, João; Gouvêa, Maria de Fátima (Org.). o Brasil Colonial 1720-1821. 1. ed. Rio de Janeiro: Civilização Brasileira, 2014.v. 1. pp.635-681.

Geiger, Pedro Pinchas (1963). Evolução da rêde urbana brasileira. Rio de Janeiro: Instituto Nacional de Estudos Pedagógicos.

Godoy, Marcelo Magalhães (2009). “Minas Gerais na república: atraso econômico, estado e planejamento". Cadernos da Escola do Legislativo, Belo Horizonte: Assembleia Legislativa do Estado de Minas Gerais, v. 11, n. 16, pp. 5-6.

Godoy, Marcelo Magalhães, Barbosa, Lidiany Silva (2008). "Uma outra modernização. Transportes em uma província não-exportadora. Minas Gerais, 1850-1870”. Economia e Sociedade, Campinas, v. 17, n. 2 (33), pp. 159-186. 
Gomes, Paulo César da Costa (1996). Geografia e Modernidade. 1. ed. Rio de Janeiro: Bertrand Brasil. Gonçalves, João Luís Traverso (2001). A geografia da imprensa em Minas Gerais no século XIX: uma conexão com as redes de cidades da província. 2001. 188 p. Tese (Doutorado) - Programa de Pósgraduação em Geografia do Instituto de Geociências, Universidade Federal de Minas Gerais, Belo Horizonte.

Graça Filho, Afonso de Alencastro. "Riqueza e negócios na primeira metade do século XIX". In: Resende, Maria Efigênia Lage de; Villalta, Luiz Carlos (Org.). História de Minas Gerais: a província de Minas, v. 1. Belo Horizonte: Autêntica Editora; Companhia do Tempo, 2013. pp.295-316.

Habermas, Jürgen (2000). O discurso filosófico da modernidade: doze lições. São Paulo: Martins Fontes.

Haesbaert, Rogério (1990). “Filosofia, Geografia e Crise da Modernidade”. Revista Terra Livre (AGB), São Paulo, v. 7, pp. 63-92.

Heinz, Flávio M (2006). Por outra história das elites. Rio de Janeiro: Editora FGV.

Holanda, Cristina Buarque (2011). Teoria das Elites. 1. ed. Rio de Janeiro: Jorge Zahar.

Harvey, David (2011). A condição pós-moderna: uma pesquisa sobre as origens da mudança cultural. 21. ed. São Paulo: Edições Loyola.

Lamounier, Maria Lúcia (2012). Ferrovias e mercado de trabalho no Brasil do século XIX. São Paulo: EDUSP.

Lamounier, Maria Lucia et al (2000). "Ferrovias, agricultura de exportação e mão-de-obra no Brasil no século XIX”. História econômica \& história de empresas, São Paulo, v. 3, n. 1, pp. 43-76.

Lanna, Ana Lúcia Duarte (1986). “O café e o trabalho livre em Minas Gerais 1870-1920”. Revista Brasileira de História, São Paulo, v. 6, n. 12, pp. 73-88.

Lemos, Celina Borges (2006). “Século XIX na paisagem cultural ouro-pretana: cotidiano, arquitetura e modernidade imperial”. In: Seminário sobre Economia Mineira: Economia, História, Demografia e Políticas Públicas, 12., 2006. Diamantina. Anais... Diamantina, 2006.

Lenharo, Alcir (1993). As tropas da moderação: o abastecimento da Corte na formação política do Brasil, 1808-1842. $2^{\mathrm{a}}$ ed. - Rio de Janeiro: Secretaria Municipal de Cultura, Turismo e Esportes, Departamento Geral de Documentação e Informação Cultural, Divisão de Editoração.

Libby, Douglas Cole (1988). Transformação e trabalho em uma economia escravista - Minas Gerais no século XIX. São Paulo: Editora Brasiliense.

Libby, Douglas Cole (1989). “Novas considerações sobre a protoindustrialização mineira dos séculos XVIII e XIX”. Revista do Departamento de História, Belo Horizonte, n. 9, pp. 149-160.

Lima, João Heraldo et al (1977). Café e indústria em Minas Gerais: 1870-1920. 1977. 136 p. Dissertação (Mestrado) - Instituto de Filosofia e Ciências Humanas, Universidade Estadual de Campinas, Campinas.

Lima, Pablo Luiz de Oliveira (2015). Ferrovia, sociedade e cultura, 1850-1930. 2 ed. Belo Horizonte: Fino Traço.

Martins, Roberto Borges (1980). A economia escravista de Minas Gerais no século XIX. Belo Horizonte: Cedeplar/UFMG.

Mata-Machado, Bernardo (1987). “O poder político em Minas Gerais: estrutura e formação”. Análise e Conjuntura, Belo Horizonte, v. 2, n. 1, pp. 68-88. 
Matos, Ralfo (1992). “Evolução urbana e formação econômica de Belo Horizonte”. Texto para discussão nº 64. Belo Horizonte: Cedeplar/UFMG. pp. 1-33.

Matos, Ralfo Edmundo da Silva; Costa, Alfredo. (Org.) (2019). Luzes e Forjas: o lugar da modernização na formação socioespacial de Minas Gerais. 1. ed. Belo Horizonte: Quixote+Do.

Matos, Ralfo; Mello, Ediméia Maria Ribeiro de (2012). “As condições estruturantes da siderurgia mineira: recursos naturais, Estado e elite instruída”. Revista GEOgrafias, Belo Horizonte, v. 8, n. 2, pp. 60-75.

Maxwell, Kenneth (1989). “Conjuração mineira: novos aspectos”. Estudos avançados, São Paulo, v. 3, n. 6, pp. 04-24.

Mello, Ediméia Maria Ribeiro de (2010). As condições estruturantes da siderurgia mineira: recursos naturais, Estado e elite instruída. 2010. 252 p. Tese (Doutorado) - Programa de Pós-graduação do Instituto de Geociências, Universidade Federal de Minas Gerais, Belo Horizonte.

Meneses, José Newton Coelho. "Homens que não mineram: oficiais mecânicos nas Minas Gerais Setecentistas”. In: Resende, Maria Efigênia Lage; Villalta, Luiz Carlos (Org.). História de Minas Gerais - as Minas Setecentistas. $1^{\text {a }}$ ed. Belo Horizonte: Autêntica/Companhia do Tempo, 2007, v. 1, pp. 377-399.

Monte-Mór, Roberto Luís (2006). “O que é o urbano, no mundo contemporâneo”. Revista Paranaense de Desenvolvimento, Curitiba, n.111, pp. 09-18.

Monte-Mór, Roberto Luís de Melo (2001). A Fisionomia das Cidades Mineradoras. Belo Horizonte: Cedeplar/Face/UFMG.

Moraes, Antônio Carlos Robert (2017). “Geografia, História e História da Geografia”. Terra Brasilis (nova série): Revista da Rede Brasileira de História da Geografia e Geografia Histórica, São Paulo, v. 2, n. 1, pp.1-8.

Moraes, Fernanda Borges de. "De arraiais, vilas e caminhos: a rede urbana das Minas coloniais". In: Resende, Maria Efigênia Lage; Villalta, Luiz Carlos (Org.). História de Minas Gerais - as Minas setecentistas. 1ed. Belo Horizonte: Autêntica/Companhia do Tempo, 2007, v. 1, pp. 55-85.

Moreira, Luciano da Silva. "Imprensa periódica e vida política". In: Resende, Maria Efigênia Lage de; Villalta, Luiz Carlos (Org.). História de Minas Gerais: a província de Minas, v. 2. Belo Horizonte: Autêntica Editora; Companhia do Tempo, 2013. pp. 65-80

Negri, Barjas (1996). Concentração e desconcentração industrial em São Paulo (1880-1990). Campinas: Unicamp.

Novais, Fernando Antônio (1979). Portugal e Brasil na Crise do Antigo Sistema Colonial (1777-1808). 1. ed. São Paulo: Hucitec.

Paiva, Clotilde Andrade (1996). População e Economia nas Minas Gerais do Século XIX. 1996. 254 p. Tese (Doutorado) - Programa de Pós-graduação em História Econômica da Faculdade de Filosofia, Letras e Ciências Humanas, Universidade de São Paulo, São Paulo.

Pires, Anderson (2004). Café, finanças e bancos: uma análise do sistema financeiro da Zona da Mata de Minas Gerais: 1889/1930. 2004. 424 p. Tese (Doutorado) - Programa de Pós-graduação em História Econômica da Faculdade de Filosofia, Letras e Ciências Humanas, Universidade de São Paulo, Juiz de Fora.

Queiroz, Bernardo Lanza; Braga, Tânia Moreira (1999). "Hierarquia urbana em um contexto de desconcentração econômica e fragmentação do território: questionamentos a partir do caso da 
rede de cidades mineira". In: Encontro Nacional da Associação Nacional de Pós-Graduação e Pesquisa em Planejamento Urbano e Regional, 8., 1999, Porto Alegre. Anais..., Porto Alegre, v. 8. Raffestin, Claude (1993). Por uma geografia do poder. Tradução: Maria Cecília França. São Paulo: Ática.

Reis, José (2005). “Epistemologia do território”. Estudos - Sociedade e Agricultura. Rio de Janeiro, v. 13, n.1, 2005, pp. 51-74.

Rodarte, Mario Marcos Sampaio (1999). O caso das Minas que não se esgotaram: a pertinácia do antigo núcleo central minerador na expansão da malha urbana da Minas Gerais Oitocentista. 1999. 179 p. Dissertação (Mestrado) - Programa de Pós-graduação em Economia do Centro de Desenvolvimento Regional e Planejamento Regional, Universidade Federal de Minas Gerais, Belo Horizonte.

Rodarte, Mario Marcos Sampaio (2008). 0 trabalho do fogo: Perfis de domicílios enquanto unidades de produção e reprodução na Minas Gerais Oitocentista. 2008. 365 p. Tese (Doutorado) - Programa de Pós-graduação em Economia do Centro de Desenvolvimento Regional e Planejamento Regional, Universidade Federal de Minas Gerais, Belo Horizonte.

Rodarte, Mário Marcos Sampaio; Paula, João Antônio; Simões, Rodrigo Ferreira (2004). "Rede de Cidades em Minas Gerais no Século XIX”. História Econômica \& História de Empresas, São Paulo, v. 7, n.1, pp. 7-45.

Rodrigues, José Carlos (1986). Ideias Filosóficas e Políticas em Minas Gerais no Século XIX. Belo Horizonte; Itatiaia; São Paulo: Editora da Universidade de São Paulo.

Santos, Dayse Lucide Silva (2015). Cidades de vidro: A fotografia de Chichico Alckmim e o registro da tradição e da mudança em Diamantina. 2015. 327 f. Tese (Doutorado). Programa de Pósgraduação em História da Faculdade de Filosofia, Letras e Ciências Humanas, Universidade Federal de Minas Gerais, Belo Horizonte.

Saraiva, Lucas Tibo (2016). "Considerações acerca das conotações do termo "elite" nas ciências sociais". Revista Alteridade - Montes Claros/MG, v. 2, n. 1, pp.30-41.

Saraiva, Luiz Fernando (2008). O Império das Minas Gerais: Café e Poder na Zona da Mata mineira, 1853-1893. Niterói: UFF/PPGH.

Schmidt, Benício Viero. "A modernização e o planejamento urbano brasileiro no século XIX". Ensaios FEE, Porto Alegre, v. 2, n. 1, pp. 19-40, 1981.

Silva, Lígia Maria Tavares da. “Trajetórias pela Geografia Histórica”. In: Bezerra, Amélia Cristina Alves et al. Itinerários Geográficos. Niterói: Eduff, 2007. pp. 71-84.

Silva, Vera Alice Cardoso (2004). “Aspectos da fundação política das elites na sociedade colonial brasileira: o 'parentesco espiritual' como elemento de coesão social”. Revista Varia História, Belo Horizonte, v. 31, pp. 97-119.

Singer, Paul (1974). Desenvolvimento econômico e evolução urbana: (análise da evolução urbana de São Paulo, Blumenau, Porto Alegre, Belo Horizonte e Recife). São Paulo: Companhia Editora Nacional.

Slenes, Robert W (1988). "Os múltiplos de porcos e diamantes: a economia escrava de Minas Gerais no século XIX”. Estudos Econômicos, São Paulo, v.18, n. 3, pp. 449-495.

Soares, Weber (2013). “As fronteiras epistemológicas entre geografia e história e a travessia conciliadora na geo-história da expansão marítima portuguesa”. Geografia, Rio Claro, v. 38, n. 1 , pp. 37-53. 
Soares, Weber (2016). "Governador Valadares e Sertões do Leste: recortes temporais resultantes da tensão entre processos de ordem vasta e de ordem local". Geografias, Belo Horizonte, v., n. 1, pp.137-150.

Soja, Edward William (1993). Geografias Pós-modernas: a reafirmação do espaço na teoria social crítica. Rio de Janeiro: Jorge Zahar.

Valle, Matheus Henrique Fernandes; Costa, Alfredo; Matos, Ralfo Edmundo da Silva (2014). "Nexos de associação entre urbanização, crescimento econômico e qualidade de vida em Minas Gerais entre 2000 e 2010”. In: Seminário sobre a Economia Mineira, 16., 2014, Diamantina. Anais..., Belo Horizonte: Cedeplar/UFMG.

Vaz, Alisson Mascarenhas (1977). “A indústria têxtil em Minas Gerais”. Revista de História, São Paulo, n. 111, pp. 101-118.

Villalta, Luiz Carlos. “As origens intelectuais e políticas da Inconfidência Mineira”. In: Resende, Maria Efigênia Lage de; Villalta, Luiz Carlos. (Org.). História de Minas Gerais - as Minas Setecentistas. Belo Horizonte: Autêntica/ Companhia do Tempo, 2007, v. 2, pp. 579-607.

Viscardi, Cláudia Maria Ribeiro. “O movimento republicano: formas de estruturação e valores políticos”. In: Resende, Maria Efigênia Lage de; Villalta, Luiz Carlos (Org.). História de Minas Gerais: a província de Minas, v. 2. Belo Horizonte: Autêntica Editora; Companhia do Tempo, 2013. pp. 97-121

Wehling, Arno (1986). Administração portuguesa no Brasil de Pombal a D. João (1777-1808). Brasília: Funcep.

Wirth, John Davis (1982). o fiel da balança: Minas Gerais na Federação Brasileira, 1889-1937. São Paulo: Paz e Terra.

\section{NOTAS}

1. Define-se como reestruturações territoriais "as transformações verificadas no espaço geográfico delimitado por relações institucionais de poder, causadas por transformações na estrutura produtiva predominante capazes de alterar a organização dos fixos e dos fluxos" (Costa, 2018: 20).

2. São muitos os trabalhos que versam sobre a origem e uso da categoria de análise geográfica "território" - porção do espaço marcada pelo exercício do poder - e não é objetivo deste trabalho retomar uma discussão teórica já bastante exaurida na geografia.

3. Define-se por reestruturação territorial "as transformações verificadas no espaço geográfico delimitado por relações institucionais de poder, causadas por transformações na estrutura produtiva predominante capazes de alterar a organização dos fixos e dos fluxos" (Costa, 2018: 20). 4. A esta justaposição David Harvey dará o nome de Palimpsesto Urbano.

5. A síntese ora apresentada é oriunda de um extenso levantamento bibliográfico que é discutido nos três capítulos da tese de Costa (2018) e no artigo de Matos e Costa (2015). Além disso, incorpora os resultados da imersão empírica realizada por Costa (2015) e do livro organizado por Matos e Costa (2019). Pontuar as contribuições dos mais de 200 autores e obras envolvidos na composição dessa síntese, separando suas contribuições por ideias apresentadas, tornaria a leitura do texto intragável. Assim, ao final de cada parágrafo, serão apresentados os principais autores que contribuíram para a sua construção.

6. Recuo colonial conservador deflagrado em Portugal após a queda do Marquês de Pombal, o ministro modernizador e muito poderoso do rei Dom José. 


\section{RESUMOS}

O artigo propõe uma narrativa-síntese sobre as modernizações em Minas Gerais desde 1750, com especial ênfase nos seus processos de urbanização e de industrialização, e na contribuição das elites. A discussão se baseia na perspectiva de que o espaço contribui ativamente nas dinâmicas sociais em suas inúmeras origens e escalas, mudanças e permanências, capacidades de atração e repulsão, e suporte para a configuração da lógica das trocas em diferentes contextos. A reflexão aponta para um processo em que a vocação agropecuária de Minas Gerais foi superada por uma industrialização oriunda de uma forte articulação política e econômica iniciada pelos inconfidentes, ao final do século XVIII, e consolidada apenas a partir da segunda metade do século XX.

The article proposes a synthesis about the modernization process of Minas Gerais brazilian state since 1750, with special emphasis on its urbanization and industrialization processes, and on the contribution of the elites. The discussion is based on understanding that the geographic space participates in social dynamics in its many origins and scales, changes and permanences, attraction and repulsion capacities, and as a base for the logic of exchanges in different contexts. The results points to a process in which the agricultural vocation of Minas Gerais was surpassed by an industrialization arising from a strong political and economic articulation initiated by the inconfident's revolutionary movement in the late eighteenth century, and consolidated only at the second half of the twentieth century.

El artículo propone una síntesis sobre el proceso de modernización del estado brasileño de Minas Gerais desde 1750, con especial énfasis en sus procesos de urbanización e industrialización y en la contribución de las élites. La discusión se basa en el marco conceptual de la epistemología del territorio, que busca comprender cómo el territorio participa en la dinámica social en sus múltiples orígenes y escalas, cambios y permanencias, capacidades de atracción y repulsión, y como base para la lógica de intercambios en diferentes contextos. Los resultados apuntan a un proceso en el que la vocación agrícola de Minas Gerais fue superada por una industrialización derivada de una fuerte articulación política y económica iniciada por el movimiento revolucionario de los inconfidentes a fines del siglo XVIII y consolidada solo en la segunda mitad del siglo XX.

L'article propose une synthèse du processus de modernisation de l'État brésilien du Minas Gerais depuis 1750, en mettant l'accent sur ses processus d'urbanisation et d'industrialisation et sur la contribution des élites. La discussion est basée sur le cadre conceptuel de l'épistémologie du territoire, qui cherche à comprendre comment le territoire participe à la dynamique sociale dans ses nombreuses origines et échelles, ses changements et ses permanences, ses capacités d'attraction et de répulsion, et comme base de la logique de échanges dans différents contextes. Les résultats indiquent un processus dans lequel la vocation agricole de Minas Gerais a été dépassée par une industrialisation résultant d'une forte articulation politique et économique initiée par le mouvement révolutionnaire de inconfidentes à la fin du XVIIIe siècle et consolidée seulement à la seconde moitié du XXe siècle. 
ÍNDICE

Índice geográfico: Minas Gerais

Mots-clés: modernisation, urbanisation, industrialisation, elites, Minas Gerais

Keywords: modernization, urbanization, industrialization, elites, Minas Gerais

Palabras claves: modernización, urbanización, industrialización, élites, Minas Gerais

Palavras-chave: modernização, urbanização, industrialização, elites, Minas Gerais

Índice cronológico: Século XVIII-Século XX

\section{AUTORES}

\section{ALFREDO COSTA}

Professor EBTT do Instituto Federal de Educação, Ciência e Tecnologia do Norte de Minas Gerais Campus Almenara

Rodovia BR 367, Km 07, s/n - Zona Rural, Almenara - MG, 39900-000

alfredo.costa@ifnmg.edu.br

\section{RALFO EDMUNDO DA SILVA MATOS}

Professor Titular da Universidade Federal de Minas Gerais

Av. Pres. Antônio Carlos, 6627 - Pampulha, Belo Horizonte - MG, 31270-901

ralfomatos@gmail.com 